\title{
Superior Canal Dehiscence Patients Have Smaller Mastoid Volume than Age- and Sex-Matched Otosclerosis and Temporal Bone Fracture Patients
}

\author{
Byoung Soo Shim ${ }^{1 *}$, Byung Chul Kang ${ }^{1 *}$, Chang-Hee Kim², Tae Su Kim ${ }^{1}$ and Hong Ju Park ${ }^{1}$ \\ ${ }^{1}$ Department of Otolaryngology, Asan Medical Center, University of Ulsan College of Medicine, Seoul, \\ ${ }^{2}$ Department of Otolaryngology, Konkuk University Hospital, Konkuk University School of Medicine, Seoul, Korea
}

Received November 9, 2012

Revised December 3, 2012

Accepted December 4, 2012

\author{
Address for correspondence \\ Hong Ju Park, MD, PhD \\ Department of Otolaryngology, \\ Asan Medical Center, \\ University of Ulsan \\ College of Medicine, \\ 88 Olympic-ro 43-gil, Songpa-gu, \\ Seoul 138-736, Korea \\ Tel $+82-2-3010-3700$ \\ Fax $+82-2-489-2773$ \\ E-mail_dzness@amc.seoul.kr \\ *These authors contributed equally to
} this article.
Background and Objectives: The purpose of the study was to compare the mastoid air-cell volume of the patients with superior semicircular canal dehiscence syndrome (SCDS) and that of the control patients with otosclerosis and temporal bone (TB) fracture. Subjects and Methods: Ten patients with SCDS were enrolled and 10 patients with bilateral otosclerosis and TB fracture were selected as control groups by age and sex matching. To measure the mastoid aircell volume, 3D reconstruction software was used. Results: In 10 patients with SCDS, the mean age was 44.5 years, ranging from 16 to 79 years $(M: F=4: 6)$. Mean mastoid air-cell volume in the SCDS side was $3319.9 \mathrm{~mm}^{3}$, whereas $4177.2 \mathrm{~mm}^{3}$ in the normal side $(p=0.022)$. Mean mastoid air-cell volume in the right side of otosclerosis patients was $6594.3 \mathrm{~mm}^{3}$ and it was not different from $6380.5 \mathrm{~mm}^{3}$ in the left side $(p=0.445)$. Mean mastoid air-cell volume in normal side of TB fracture was $6477.2 \mathrm{~mm}^{3}$. The mastoid air-cell volume in the SCDS side was significantly smaller than that of otosclerosis and TB fracture patients $(p=0.009, p=0.002$, respectively). The mastoid air-cell volume in the normal side of SCDS was significantly smaller than that of TB fracture $(p=0.019)$, but not significant with that of otosclerosis $(p=0.063)$. Conclusions: Our findings revealed that the mastoid air-cell volume in the SCDS side was significantly smaller than control group, which suggest that the decreased mastoid pneumatization is closely related to the generation of SCDS.

Korean J Audiol 2012;16:120-123

\section{Introduction}

Superior semicircular canal dehiscence syndrome (SCDS) is a recently recognized clinical condition, which was initially described by Minor, et al. ${ }^{1)}$ The syndrome usually encompasses a constellation of vestibular and audiological symptoms, such as sound and/or pressure induced vertigo and oscillopsia, along with conductive hearing loss and autophony, and typically manifests as sound and/or pressure induced nystagmus at the plane of the superior semicircular canal (SSC).-4)

The proposed underlying mechanism involves the existence of a dehiscence at the apex of the SSC (third mobile window), in addition to the round and oval windows of the osseous cochlea, which in effect potentiates the transmission of sudden changes in the middle and/or intracranial pressure, thus altering the related neural firing rates of the vestibular system, and may also alter inner ear fluid dynamics, causing dissemination of the acoustic energy. ${ }^{5,6}$

While the classic presentation can be suspected on clinical and audiometric data, imaging plays an important role in the evaluation of these patients. Advances in computed tomography (CT) now allow high resolution images to demonstrate the bony defect, while multiplanar reformations can also aid in the radiologic diagnosis. ${ }^{7-9)}$

Despite the several investigations on this condition, there are no clear causes of SCDS. Certainly, a congenital/developmental basis for the condition has been described. ${ }^{9-13)}$ There was a report describing the development of SCDS from an intact ear, confirmed by serial follow-up CT scans. ${ }^{14)}$ In that study, osteomyelitis and increased bony absorption associated with chronic brain pulsation might be one of the possible causes of SCDS. Because inflammatory process is related to the de- 
creased mastoid air-cell volume, ${ }^{15,16)}$ we wanted to compare the mastoid air-cell volume of the patients with SCDS and that of the age- and sex-matched patients with otosclerosis and temporal bone (TB) fracture, who are supposed to represent normal mastoid pneumatization.

\section{Subjects and Methods}

10 patients with SCDS confirmed by symptoms, signs, vestibular evoked myogenic potential and TB CT imaging were enrolled. To compare the mastoid air-cell volume, the otosclerosis and TB fracture patients identified in the TB CT were selected as control groups. The selection was made by age and sex matching. In the control groups, the otosclerosis was identified in both sides, and with no other pathology, such as chronic otitis media (COM) and middle ear effusion. This study was approved by the Institutional Review Board of our institute and followed the recommended guidelines.

High-resolution TB CT scans were performed using a 64 row detector CT scanner (Siemens, Medical System, Erlanger, Germany). Images were helically acquired without contrast and were reconstructed using a bone plus algorithm. The axial plane images were acquired using a $0.6 \mathrm{~mm}$ section thickness at $200 \mathrm{~mA}$ and $120.0 \mathrm{kV}$. The coronal and oblique sagittal reconstruction images, which were parallel to the superior semicircular canal, were acquired using $0.4 \mathrm{~mm}$ interval reconstructions. All of the images were evaluated on a Diagnostic Petavision pacs station (Emsoma, Seoul, Korea). To measure the mastoid air-cell volume, we used 3D reconstruction software. Continuous non-overlapping sections of TB CT scan images were used. The imaging data were stored in a Digital Imaging and Communication in Medicine file and then imported to a personal computer running Vworks 4.0 software (Cybermed, Seoul, Korea). When performing reconstruction using a surface rendering algorithm, the selection of the window thresholds were -1024 to -318 Hounsfield Units. The volume of mastoid air-cell was automatically calculated in the 3D reconstruction (Fig. 1).

Statistical analysis was conducted using Wilcoxon signed rank test to compare volume between the SCDS side and the normal side in SCDS patients, and left and right side of the otosclerosis patients. The differences of mastoid air-cell volume in the SCDS, otosclerosis and TB fracture were determined using the Kruskal-Wallis test and Mann-Whitney U test. All statistical analyses were performed using SPSS 20.0 software (SPSS, IBM corp., Armonk, NY, USA), and the $p$ values $<0.05$ were considered significant.

\section{Results}

Ten patients with SCDS were enrolled. Sex ratio was $4: 6$ (male : female). The mean age was 44.5 years, ranging from 16 to 79 years. The sides of SCDS were right in 4 and left in 6 .

Mean mastoid air-cell volume in SCDS side was 3319.9 $\mathrm{mm}^{3}$, whereas $4177.2 \mathrm{~mm}^{3}$ in the normal side (Table 1). There was a significant difference of the mastoid air-cell volume between the lesion side and the normal side of SCDS patients $(p=0.022$, Wilcoxon signed rank test).

Mean mastoid air-cell volume of otosclerosis patients was $6594.3 \mathrm{~mm}^{3}$ in the right side and $6380.5 \mathrm{~mm}^{3}$ in the left side (Table 1). And there was no significant difference of mastoid aircell volume between the right and left sides ( $p=0.445$, Wilcoxon signed rank test). Mean mastoid air-cell volume in normal side of TB fracture was $6477.2 \mathrm{~mm}^{3}$ (Table 1). There is no difference between the mastoid air-cell volume of the otosclerosis and that of TB fracture patients $(p=0.684)$.

The mastoid air-cell volume of the SCDS (both sides) showed significant difference compared to that in any side of the oto-

Fig. 1. Three-dimensional reconstruction of computed tomography scans was performed using a surface rendering algorithm. The volume of mastoid air-cell was automatically calculated by software.

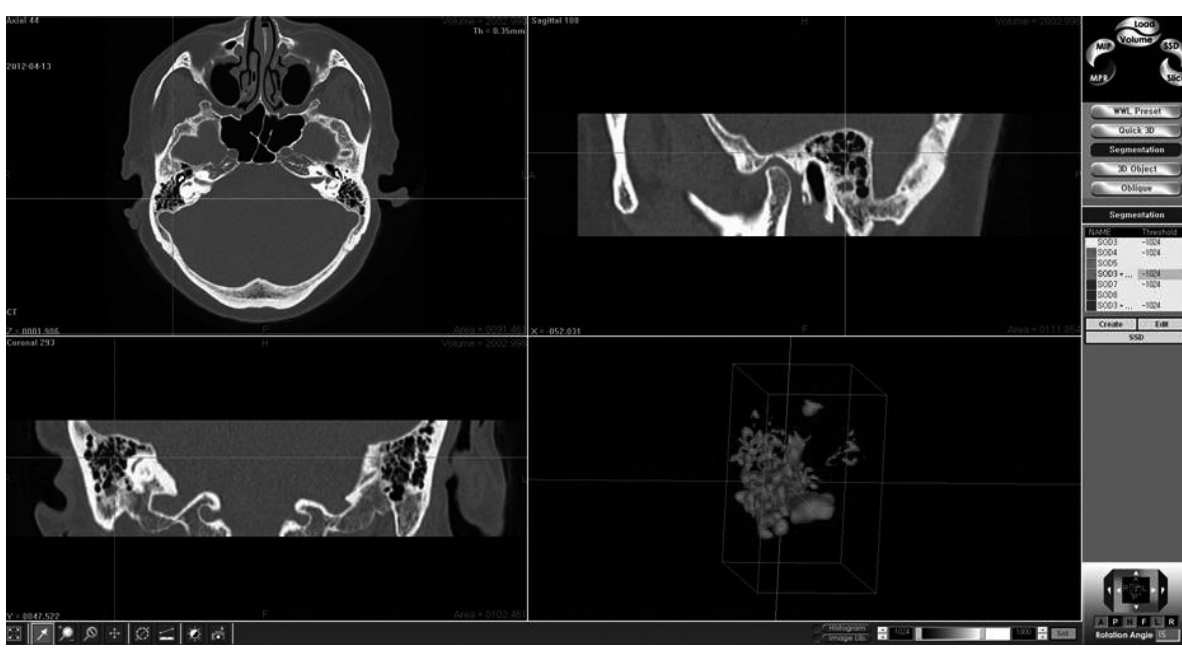


Table 1. The mastoid air-cell volume $\left(\mathrm{mm}^{3}\right)$ in patients with superior semicircular canal dehiscence syndrome, otosclerosis and temporal bone fracture

\begin{tabular}{|c|c|c|c|c|c|c|c|}
\hline \multirow{2}{*}{ Case no. } & \multirow{2}{*}{ Sex } & \multirow{2}{*}{ Age } & \multicolumn{2}{|c|}{ SCDS } & \multicolumn{2}{|c|}{ Otosclerosis } & \multirow{2}{*}{$\begin{array}{l}\text { TB fracture } \\
\text { Normal ears }\end{array}$} \\
\hline & & & SCDS ears & Normal ears & Right & Left & \\
\hline 1 & $F$ & 34 & 2524.6 & 4806.1 & 2708.9 & 3017.2 & 8965.6 \\
\hline 2 & $\mathrm{~F}$ & 59 & 2000.7 & 2003.0 & 7412.9 & 6760.6 & 5822.3 \\
\hline 3 & M & 16 & 1846.9 & 4409.4 & 5561.7 & 4480.4 & 6344.6 \\
\hline 4 & $M$ & 52 & 5643.5 & 6049.7 & 8491.5 & 7554.5 & 8826.8 \\
\hline 5 & $\mathrm{~F}$ & 79 & 4321.4 & 4526.9 & 4557.6 & 4789.3 & 4762.2 \\
\hline 6 & $\mathrm{~F}$ & 43 & 3157.6 & 4166.9 & 8578.5 & 9074.9 & 5425.6 \\
\hline 7 & $\mathrm{~F}$ & 39 & 1944.5 & 2939.8 & 6753.1 & 5207.5 & 5288.7 \\
\hline 8 & $\mathrm{~F}$ & 38 & 6159.1 & 5459.1 & 3246.4 & 3575.6 & 5750.1 \\
\hline 9 & M & 44 & 956.7 & 1656.2 & 4753.1 & 7265.3 & 9197.5 \\
\hline 10 & $M$ & 41 & 4643.6 & 5755.0 & 13879.3 & 12079.5 & 4388.6 \\
\hline Mean & & & 3319.9 & 4177.2 & 6594.3 & 6380.5 & 6477.2 \\
\hline
\end{tabular}

SCDS: superior semicircular canal dehiscence syndrome, TB: temporal bone, F: female, $M$ : male

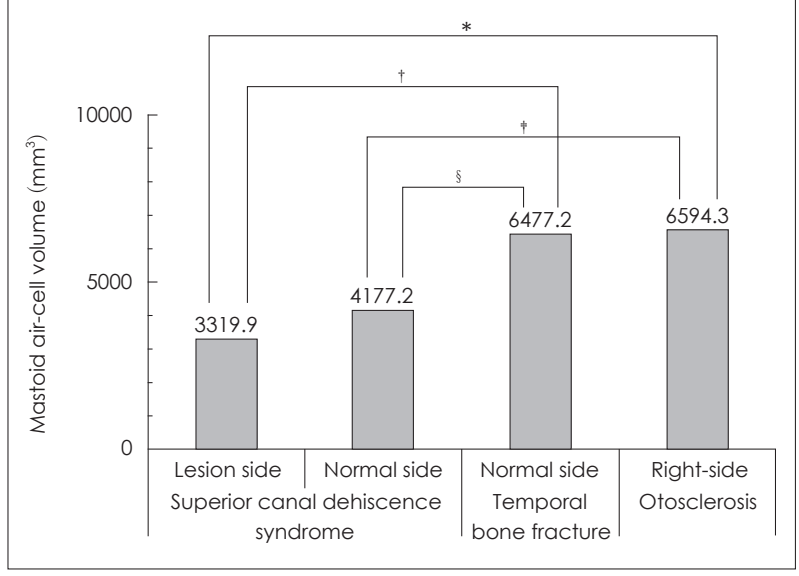

Fig. 2. Comparison of the mastoid air-cell volumes between the superior canal dehiscence syndrome (lesion and normal side), temporal bone fracture (normal side) and otosclerosis (right-side) patients. ${ }^{*} p=0.009,{ }^{\dagger} p=0.002,{ }^{\ddagger} p=0.063,{ }^{\$} p=0.019$ in Mann-Whitney U test.

sclerosis patients ( $p=0.013$, Kruskal-Wallis test). In the posthoc analysis, the mastoid air-cell volume in SCDS side was significantly smaller than those of otosclerosis patients $(p=$ 0.009, Mann-Whitney U test)(Fig. 2). However, the difference between the mastoid air-cell volume in the normal side of SCDS patients and that of otosclerosis patients was not significant ( $p=0.063$, Mann-Whitney U test).

Similarly, the mastoid air-cell volume of the SCDS (both sides) showed significant difference compared to that in TB fracture patients ( $p=0.006$, Kruskal-Wallis test). In the post-hoc analysis, the mastoid air-cell volume in SCDS side and normal side of SCDS patients were significantly smaller than that of TB fracture patients ( $p=0.002, p=0.019$, respectively, MannWhitney U test)(Fig. 2).

\section{Discussion}

The decrease of mastoid air-cell volume could be seen sev- eral conditions, such as otitis media with effusion, COM, and cholesteatoma. ${ }^{15,16)}$ Many studies reported that the inflammatory process is related to the decreased mastoid air-cell volume. Our results demonstrated significantly smaller mastoid air-cell volume in the SCDS side than in that of the otosclerosis patients and TB fracture patients ( $p=0.009, p=0.002$, respectively). The mastoid air-cell volume $\left(4177.2 \mathrm{~mm}^{3}\right)$ in the normal side of SCDS patients was smaller than that $\left(6594.3 \mathrm{~mm}^{3}\right.$ in the right ear and $6380.5 \mathrm{~mm}^{3}$ in the left ear) of the otosclerosis patients, although it was not significant $(p=0.063)$. But, the mastoid aircell volume in the normal side of SCDS patients significantly smaller than TB fracture patients $\left(4177.2 \mathrm{~mm}^{3}\right.$ vs. $6477.2 \mathrm{~mm}^{3}$, $p=0.019$ ). Because no patients with SCDS in this study had soft tissue density in the mastoid in TB CT scans, suggesting there is no active inflammation in the mastoid, inflammatory process (acute otitis media or middle ear effusion) in the early childhood could have had a role in the decreased mastoid aircell volume in the SCDS ear.

It remains unclear whether SCDS is a congenital/developmental disorder or whether it is acquired. It has been reported that TB specimens from infants show uniformly thin bone over the superior canal in the middle fossa at birth, with gradual thickening until 3 years of age, and that SCDS may arise from failure of postnatal bone development. ${ }^{9)}$ Tsunoda and Terasaki ${ }^{17)}$ has described the embryological basis for dehiscence. The precartilage bordering the developing membranous labyrinth dedifferentiates into loose reticular mesenchyme. If the otocyst is situated close to the developing brain during this stage, there is inadequate space for the growth of the superior surface of the superior semicircular canal as the otocyst may lie against the dura. Hindering gradual thickening of the superior canal roof by otitis media before the age of 3 , associated with the decreased mastoid pneumatization, may make the superior canal roof thin enough. Additionally, SCDS may be generated by ch- 
ronic brain pulsation and the pressure exerted by the temporal lobe on the middle cranial fossa. ${ }^{9)}$

However, another study demonstrated that the radiologic prevalence of SCDS among older age groups increases, suggesting that SCDS is more commonly an acquired rather than developmental condition. ${ }^{18)}$ Chronic bone inflammation by previous otitis media in childhood, which can be identified as having decreased mastoid volume, may render the bone overlying the superior canal susceptible to brain pulsation or the pressure from the temporal lobe, resulting in the generation of SCDS.

\section{Conclusion}

Our findings revealed that the mastoid air-cell volume in the SCDS side was significantly smaller than that of otosclerosis and TB fracture patients, furthermore the volume in the normal side of SCDS patients was significantly smaller than that of TB fracture patients, which suggest that the decreased mastoid pneumatization is closely related to the generation of SCDS, whether SCDS is a congenital/developmental disorder or whether it is acquired.

\section{REFERENCES}

1) Minor LB, Solomon D, Zinreich JS, Zee DS. Sound- and/or pressureinduced vertigo due to bone dehiscence of the superior semicircular canal. Arch Otolaryngol Head Neck Surg 1998;124:249-58.

2) Minor LB. Clinical manifestations of superior semicircular canal dehiscence. Laryngoscope 2005;115:1717-27.

3) Mikulec AA, McKenna MJ, Ramsey MJ, Rosowski JJ, Herrmann BS, Rauch SD, et al. Superior semicircular canal dehiscence presenting as conductive hearing loss without vertigo. Otol Neurotol 2004;25: 121-9.

4) Cremer PD, Minor LB, Carey JP, Della Santina CC. Eye movements in patients with superior canal dehiscence syndrome align with the abnormal canal. Neurology 2000;55:1833-41.

5) Friedland DR, Michel MA. Cranial thickness in superior canal de- hiscence syndrome: implications for canal resurfacing surgery. Otol Neurotol 2006;27:346-54.

6) Minor LB, Carey JP, Cremer PD, Lustig LR, Streubel SO, Ruckenstein MJ. Dehiscence of bone overlying the superior canal as a cause of apparent conductive hearing loss. Otol Neurotol 2003;24: 270-8.

7) Belden CJ, Weg N, Minor LB, Zinreich SJ. CT evaluation of bone dehiscence of the superior semicircular canal as a cause of soundand/or pressure-induced vertigo. Radiology 2003;226:337-43.

8) Williamson RA, Vrabec JT, Coker NJ, Sandlin M. Coronal computed tomography prevalence of superior semicircular canal dehiscence. Otolaryngol Head Neck Surg 2003;129:481-9.

9) Carey JP, Minor LB, Nager GT. Dehiscence or thinning of bone overlying the superior semicircular canal in a temporal bone survey. Arch Otolaryngol Head Neck Surg 2000;126:137-47.

10) Zhou G, Ohlms L, Liberman J, Amin M. Superior semicircular canal dehiscence in a young child: implication of developmental defect. Int J Pediatr Otorhinolaryngol 2007;71:1925-8.

11) Hirvonen TP, Weg N, Zinreich SJ, Minor LB. High-resolution CT findings suggest a developmental abnormality underlying superior canal dehiscence syndrome. Acta Otolaryngol 2003;123:477-81.

12) Morimoto AK, Wiggins RH 3rd, Hudgins PA, Hedlund GL, Hamilton B, Mukherji SK, et al. Absent semicircular canals in CHARGE syndrome: radiologic spectrum of findings. AJNR Am J Neuroradiol 2006;27:1663-71.

13) Satar B, Mukherji SK, Telian SA. Congenital aplasia of the semicircular canals. Otol Neurotol 2003;24:437-46.

14) Bae JS, Lim HW, An YS, Park HJ. Acquired superior semicircular canal dehiscence confirmed by sequential CT scans. Otol Neurotol 2012. In Press.

15) Csakanyi Z, Katona G, Josvai E, Mohos F, Sziklai I. Volume and surface of the mastoid cell system in otitis media with effusion in children: a case-control study by three-dimensional reconstruction of computed tomographic images. Otol Neurotol 2011;32:64-70.

16) Cinamon U. The growth rate and size of the mastoid air cell system and mastoid bone: a review and reference. Eur Arch Otorhinolaryngol 2009;266:781-6.

17) Tsunoda A, Terasaki O. Dehiscence of the bony roof of the superior semicircular canal in the middle cranial fossa. J Laryngol Otol 2002; 116:514-8.

18) Nadgir RN, Ozonoff A, Devaiah AK, Halderman AA, Sakai O. Superior semicircular canal dehiscence: congenital or acquired condition? AJNR Am J Neuroradiol 2011;32:947-9. 